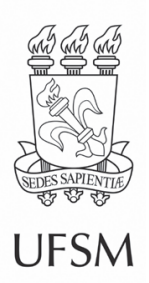

\title{
Artigos
}

\section{Germinação de sementes e morfologia de plântulas de espécies pioneiras da várzea amazônica}

\author{
Seed germinations and seedling morphology of pioneers species of the \\ Amazon floodplain
}

\author{
Ivone Neri Santiago $1 \bullet$, Maria Teresa Fernandez Piedade $1 \bullet$, \\ Bianca Weiss ${ }^{1 \oplus}$, Layon Oreste Demarchi ${ }^{\circ}$, Aline Lopes $"{ }^{\prime \prime}$ \\ ' Instituto Nacional de Pesquisas da Amazônia, Manaus, AM, Brasil \\ " Universidade de Brasília, Brasília, DF, Brasil
}

\section{RESUMO}

As florestas de várzea estão sendo afetadas ao longo de séculos por diversas atividades antrópicas que põem em risco a integridade desse ecossistema, demandando estudos que propiciem sua conservação e restauração. O objetivo deste estudo foi caracterizar a morfologia de plântulas de três espécies pioneiras presentes na floresta de várzea do lago Catalão - AM: Cecropia latiloba Miq. (Urticaceae), Ficus insipida Willd. (Moraceae) e Allophylus amazonicus (Mart.) Radlk. (Sapindaceae) como subsídio para criar ferramentas para sua identificação em campo. Para cada espécie foram coletadas sementes de três diferentes matrizes, as quais foram processadas e acondicionadas em bandejas para germinação em solo proveniente do local de coleta. Foram analisadas e descritas morfologicamente cada fase de desenvolvimento até a formação de plântulas e mudas. Nas três espécies, a germinação foi classificada como epígea e fanerocotiledonar, e todas apresentaram diferenças morfológicas nos cotilédones, eófilos e catáfilos, permitindo a separação visual das mesmas. Os resultados indicam que a morfologia foliar é uma importante ferramenta para auxiliar a identificação e diferenciação desde as fases iniciais do desenvolvimento das plântulas. Esse conhecimento pode subsidiar estratégias de manejo como a formação de banco de plântulas para a recuperação de áreas degradadas de várzea.

Palavras-chave: Floresta alagável; Estabelecimento; Germinação; Ecologia morfofuncional; Sucessão florestal 


\section{ABSTRACT}

The white-water floodplain forests (várzea) have been affected for centuries by various human activities that endanger the integrity of this ecosystem, demanding studies that provide conservation and restoration. The objective of this study was to characterize the seedling morphology of three pioneer species present in the floodplain forest of Catalão Lake - AM: Cecropia latiloba Miq. (Urticaceae), Ficus insipida Willd. (Moraceae), Allophylus amazonicus (Mart.) Radlk. (Sapindaceae), as a subsidy to create tools for the field identification. Seeds were collected from three different matrices, these were processed and placed in trays for germination in soil from the collection site. Each developmental phase until the seedling formation was analyzed and morphologically described. In the three species, the germination was classified as epigeal and phanerocotyledonous, and all showed morphological differences in cotyledons, eophylls and cataphylls, allowing the visual separation of them. Our results indicate that the leaf morphology is an important tool to help the identification and differentiation from the early stages of the seedling development. This knowledge can support management strategies such as the formation of a seedling bank for the recovery of degraded várzea forests areas.

Keywords: Floodplain forest; Establishment; Germination; Morphofunctional ecology; Forest succession

\section{INTRODUÇÃO}

As florestas alagáveis cobrem uma área de aproximadamente 750.000 km² da região amazônica (MELACK; HESS, 2010; WITTMANN; JUNK, 2016). Dentre essas florestas, as várzeas, inundáveis por rios de águas brancas (PRANCE, 1980), são aquelas de maior fertilidade por se originarem na região Andina e Pré-Andina, onde os processos de erosão são intensos e responsáveis pelo carreamento de grandes quantidades de ricos sedimentos em suspensão (JUNK et al., 2011). Essas áreas estão sujeitas a uma fase aquática e uma fase terrestre anuais, devido ao pulso de inundação, que é a força motriz controlando os componentes bióticos e abióticos dos ambientes alagáveis (SIOLI, 1984; JUNK; BAYLEY; SPARKS, 1989).

Variações na topografia do relevo nas florestas de várzea resultam em diferenças no número de dias de inundação anual, levando à formação de gradientes sucessionais de composição de espécies, diversidade e estrutura da floresta (FERREIRA et al., 2010; WITTMANN; SCHÖNGART; JUNK, 2010). Isso ocorre porque a inundação prolongada altera a fisiologia das espécies, levando à redução da atividade fotossintética, formação de raízes adventícias, hipertrofia do caule (WALDHOFF; JUNK; FURCH, 1998; PAROLIN, 
2001; WITTMANN; PAROLIN, 2005), e a formação de anéis de crescimento (WORBES, 1989; 1997; NEVES et al., 2019). Assim, com base no tempo médio e na profundidade da inundação, as várzeas são classificadas em várzea baixa e várzea alta, havendo entre 5 e 23\% de similaridade na composição de espécies entre os dois tipos florestais (WITTMANN; JUNK; PIEDADE, 2004). Na várzea alta, a coluna de água máxima é de 3 metros, correspondendo a poucos dias (30-60) de inundação; na várzea baixa, contudo, as inundações podem atingir alturas entre 7 e 8 metros, correspondendo ao período de submersão de até 228 dias por ano (WITTMANN; ANHUF; JUNK, 2002).

Devido ao crescimento mais intenso das árvores de várzea em relação a outros ecossistemas amazônicos, elas estão sendo utilizadas para o extrativismo madeireiro especialmente na Amazônia Ocidental, onde contribuem com mais de 60\% da madeira que chega aos mercados (SCHÖNGART et al., 2007). Além disso, outras pressões antrópicas causam a perda de habitat e suas comunidades arbóreas, como é o caso da pecuária e agricultura, especialmente em larga escala (PIEDADE et al., 2013). Essa situação se contrapõe aos planos de recuperação de áreas degradadas para a Amazônia (ECODEBATE, 2017), e aponta para a necessidade de planos de recuperação mais eficazes.

Para proceder à recuperação de áreas alteradas, inicialmente é necessário o conhecimento da composição florística, dos processos de estabelecimento e o reconhecimento em campo das espécies pioneiras que modificam a paisagem e contribuem para o estabelecimento de espécies secundárias (WITTMANN et al., 2007). Essas informações podem propiciar a rápida recolonização de áreas de várzea, tanto pela produção de mudas de espécies-chave, quanto pela coleta de plântulas em campo (OLIVEIRA, 2019). Entretanto, para isso, o conhecimento das características morfológicas que auxiliem a identificação das espécies em campo, ainda incipiente, deve ser ampliado. Para suprir essa lacuna, neste estudo foi investigado o desenvolvimento morfológico foliar de plântulas de três espécies pioneiras comumente presentes em áreas de várzea e para as quais há escassez de informações: Cecropia latiloba Miq. (Urticaceae), Allophylus amazonicus (Mart.) Radlk. (Sapindaceae) e Ficus insipida Willd. (Moraceae). 


\section{MATERIAL E MÉTODOS}

\subsection{Caracterização das espécies}

As três espécies escolhidas são de sucessão inicial das áreas de várzea, ocupando as áreas mais baixas e mais expostas ao alagamento, como consequência possuem diferentes adaptações para a sobrevivência a grandes períodos submersas, como mudanças na formação de raízes (raízes adventícias), formação de lenticelas, diminuição da respiração foliar e taxas fotossintéticas levando à redução de crescimento e à formação de anéis de crescimento, perda ou diminuição de folhas durante o alagamento, fenologia adaptada na qual a produção de frutos se dá durante a época de cheia dos rios e consequente dispersão hidrocórica e ictiocórica (PAROLIN, 2001; SCHÖNGART et al., 2002).

Cecropia latiloba Miq. (Urticaceae): espécie de hábito arbóreo, altamente eficiente na colonização de locais recém-abertos, tolerante à alta irradiação e deposição de sedimentos, características adaptativas que permitem que os indivíduos formem manchas densas e monoespecíficas ao longo dos grandes rios de várzea amazônicos (PAROLIN, 2002). Ocorre também nas regiões centro-oeste e nordeste do Brasil, além de países vizinhos como Bolívia, Colômbia, Equador, Guiana, Peru, Suriname e Venezuela (BERG; ROSSELLI, 2005).

Ficus insipida Willd.(Moraceae): espécie de hábito arbóreo, de rápido crescimento, ocupando os estágios iniciais de sucessão das áreas de várzea baixa. É considerada uma das espécies mais importantes economicamente para o manejo florestal madeireiro comunitário da Reserva de Desenvolvimento Sustentável de Mamirauá; a espécie é amplamente distribuída na América do Sul e Central (SCHÖNGART et al., 2007).

Allophylus amazonicus (Mart.) Radlk. (Sapindaceae): espécie de hábito arbustivo a arbóreo, abundante nos estágios iniciais de sucessão, mais comumente em áreas de várzea baixa sujeita a altos níveis de inundação, ocorre na região norte do país e nos países vizinhos Colômbia, Equador, Guiana, Peru e Venezuela (COELHO, 2014). 


\subsection{Coleta de material e processamento}

Os frutos das três espécies foram coletados no Lago Catalão, situado no município de Iranduba, próximo à cidade de Manaus, Amazonas (0310'04" S e 5954'45" W), na Amazônia Central brasileira. O lago cobre uma área de aproximadamente 20 km² e está localizado na confluência dos rios Negro e Solimões (Figura 1).

Figura 1 - Localização do Lago Catalão, na confluência dos rios Negro e Solimões, em Iranduba, Amazonas (UTM Zona 20S - Datum WGS 84)

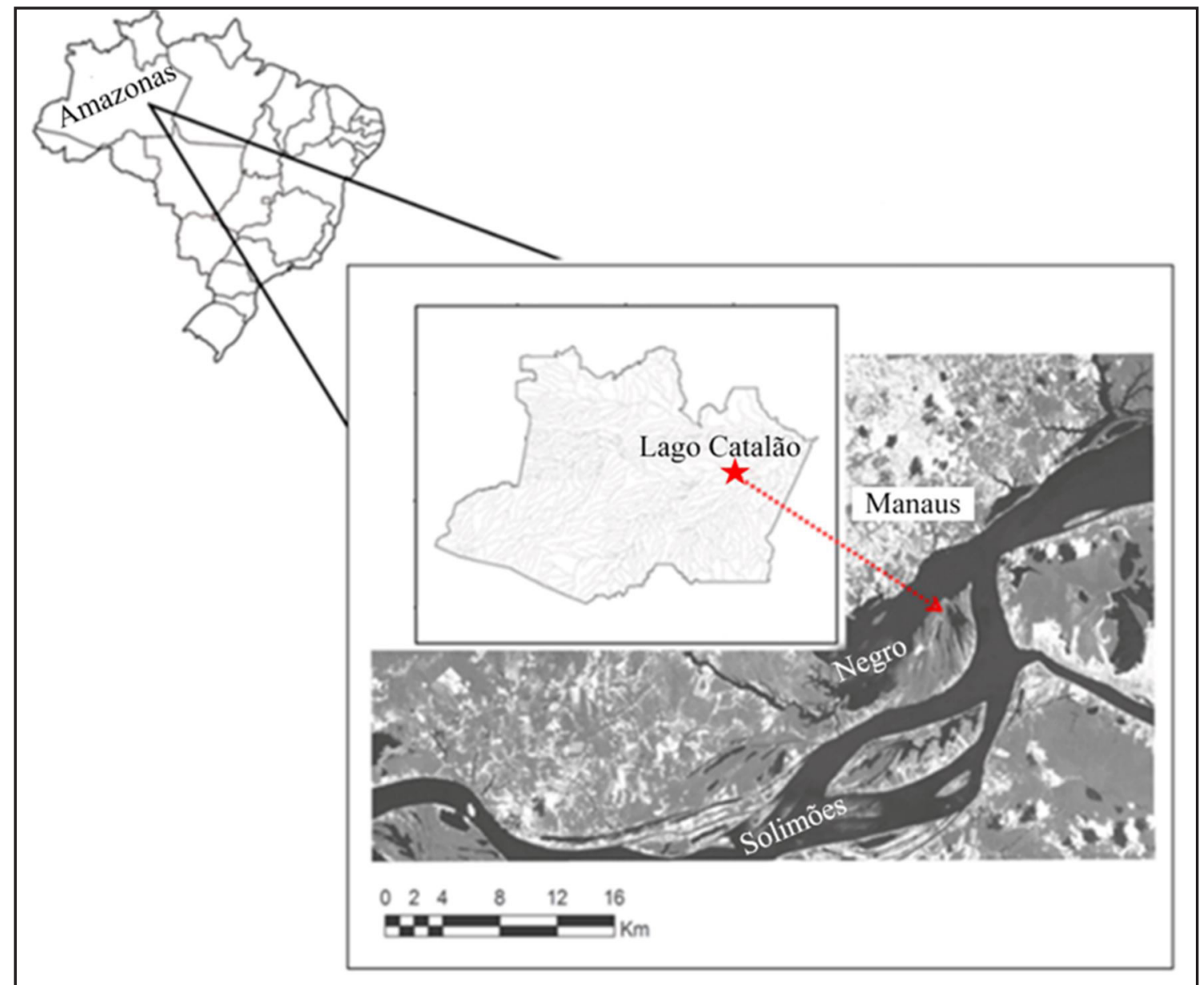

Fonte: Angélica Resende (2020)

A coleta de frutos de Cecropia latiloba e Ficus insipida foi realizada durante o mês de abril e de Allophylus amazonicus no mês de agosto do ano de 2014. As coletas foram feitas em três diferentes indivíduos de cada espécie selecionada, distantes entre si no 
mínimo 500 metros; frutos maduros encontrados flutuando no interior da floresta alagada também foram coletados. Com o intuito de evitar possíveis interferências nos testes de germinação devido à imaturidade embrionária das sementes, foram coletados frutos maduros definidos a partir do tamanho e coloração já descritos segundo a literatura (WITTMANN et al., 2010). O material foi acondicionado em sacos plásticos abertos e enviado ao laboratório do Projeto INPA/Max-Planck, em Manaus, no qual os frutos foram despolpados para a obtenção das sementes.

A semeadura ocorreu em um período máximo de 24 horas após a coleta. Foram semeadas 30 sementes de cada espécie em bandejas contendo solo de várzea retirado do mesmo local de estudo. A germinação e o desenvolvimento das plântulas foram acompanhados diariamente durante 28 dias em casa de vegetação do projeto "Ecologia, Monitoramento e Uso Sustentável de Áreas Úmidas - MAUA" (CODAM/ INPA), em ambiente sombreado (sombrite a 50\%) com temperatura ambiente e rega diária de água de poço artesiano.

A morfologia foi acompanhada após a germinação (protrusão da radícula do embrião) durante toda a fase de plântula até a fase de muda, aproximadamente 10 meses. O termo "plântula" foi utilizado quando as plantas apresentaram os cotilédones e o primeiro par de eófilos (primeiro par de folhas), e o termo "muda" foi empregado para o estágio em que os eófilos atingiram um desenvolvimento aproximando ao metáfilo (folhas adultas) (LOPES; ROSA; PIEDADE, 2012). As descrições referentes à morfologia externa das folhas foram baseadas em Leaf Architecture Working Group (HICHEY et al., 1999; GONÇALVES; LORENZI, 2011; SOUZA, 2009). O monitoramento das fases foi fotografado por meio de câmera digital e a cada diferenciação foliar retiraramse três plântulas inteiras, que foram fotografadas após a lavagem e colocadas em FAA 50\% (JOHANSEN, 1940) para posterior visualização e descrição de nervuras.

As nervações foram observadas nos cotilédones, eófilos e catáfilos. As nervações terciárias foram descritas somente nas mudas após 10 meses de plantio nos catáfilos que são folhas intermediárias que se encontram entre os eófilos e as 
folhas propriamente ditas adultas. Ao final sumarizaram-se por meio de uma matriz de presença (1), ausência (0), não visualizados (*) os caracteres morfológicos observados nas folhas de Cecropia latiloba (CEC), Ficus insipida (FIC) e Allophylus amazonicus (ALL).

\section{RESULTADOS}

Todas as sementes das três espécies estudadas germinaram (83,3 a 100\% de germinação) (Figura 2) e puderam ser estudadas até a fase de muda (Figura 4. D, H e L). Nenhuma das espécies apresentou período de dormência. O tempo de germinação após a semeadura variou entre as espécies: Cecropia latiloba germinou entre o $5^{\circ}$ a $28^{\circ}$ dia após a semeadura, Ficus insipida entre o $4^{\circ}$ e o $7^{\circ}$ dia, e Allophylus amazonicus entre o $4^{\circ}$ e o $9^{\circ}$ dia, respectivamente (Figura 2 ).

Figura 2 - Germinação acumulada ao longo de 28 dias de experimento, das espécies: Cecropia latiloba, Ficus insipida e Allophylus amazonicus

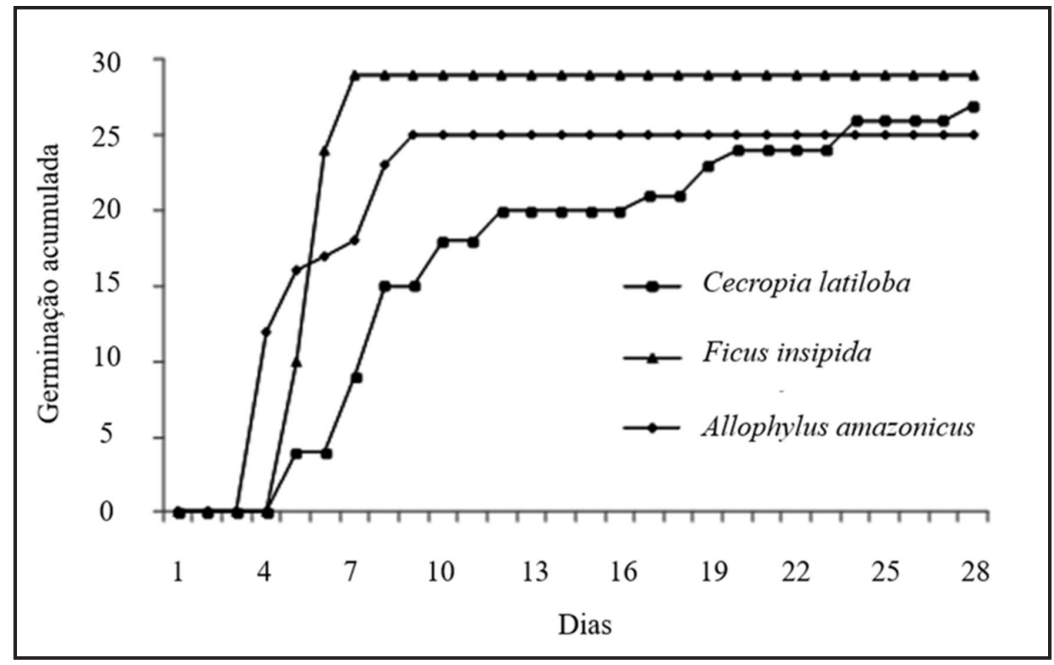

Fonte: Autores (2020)

A germinação foi classificada como epígea e fanerocotiledonar para as três espécies (Figura 3A, D e G). Em relação à morfologia das plântulas, aos 52 dias após a germinação Cecropia latiloba ainda apresentava 90\% das plântulas com cotilédones foliáceos e tricomas presentes no limbo e pecíolo, de formato largo-elíptico com ápice 
retuso e filotaxia oposta (Figuras 3B e 4A). Os eófilos aos 52 dias apresentaram folhas simples elípticas com presença de tricomas em todo o limbo, margens levemente crenadas com ápice e base cuneada, de filotaxia alterna (Figuras 3B e 4B). Aos 162 dias, os catáfilos apresentaram-se simples de filotaxia alternada, ápice e base cuneada com margens serrilhadas (Figuras 3C e 4C).

Figura 3 - Cecropia latiloba aos (A) 5 dias; (B) 52 dias; (C) 162 dias; Ficus insipida aos (D) 5 dias; (E) 52 dias; (F) 162 dias; Allophylus amazonicus aos (G) 5 dias; (H) 8 dias; (I) 35 dias; () 162 dias. $(\mathrm{R}=$ radícula; $\mathrm{FO}=$ eófilos; $\mathrm{FC}=$ folha cotiledonar; $\mathrm{CF}=$ catáfilos; $\mathrm{ET}=$ estípulas; NV = Nível do substrato)

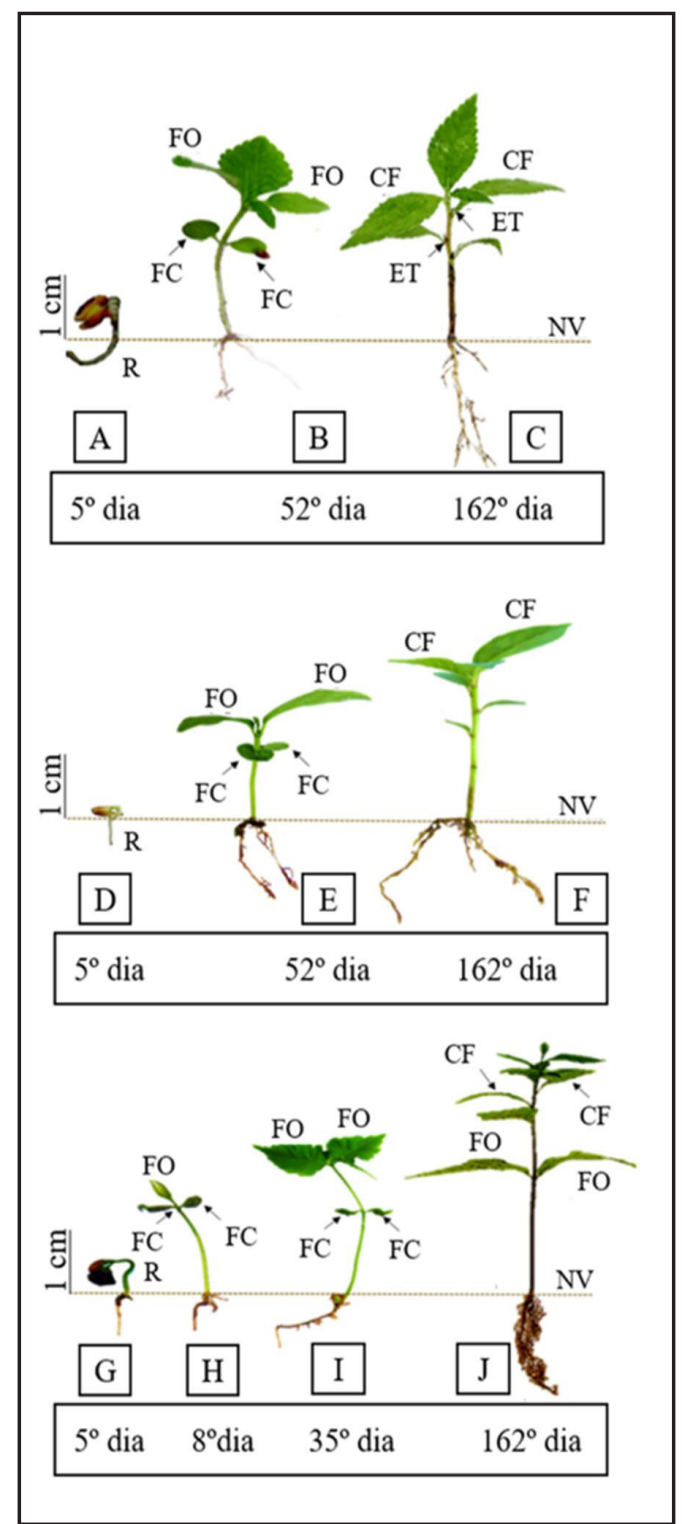

Fonte: Autores (2020) 
Ficus insipida aos 52 dias de plantio ainda apresentava cotilédones foliáceos de forma largo-elíptica, com ápice e base arredondada e filotaxia oposta (Figuras 3E e 4E) e eófilos de folhas simples elípticas de margens inteiras, com ápice e base cuneada e filotaxia oposta (Figuras 3E e 4F). Aos 162 dias, a espécie apresentou catáfilos de filotaxia alternada, ápice e base cuneada com margens inteiras (Figuras 3F e 4G).

Allophylus amazonicus aos 5 dias de plantio (Figura 3G) ainda apresentava cotilédones envolvidos pelo tegumento da semente que se desprende parcialmente a partir dos 7 a 8 dias de semeadura (Figura 3H). Os cotilédones são de reserva, crassos, estreito-elípticos, com margens dobradas levemente sinuadas (Figura 4I). Durante a morfogênese dos cotilédones surge entre eles um par de eófilos de coloração verde com presença de tricomas no limbo e em sua nervação principal (Figura $3 \mathrm{H}$ ), aos 35 dias esses eófilos se apresentam de forma deltoide, com base truncada e ápice cuneado de margens crenadas e filotaxia oposta (Figuras 3l e 4J). Aos 162 dias de plantio, a espécie apresentou catáfilos, de filotaxia alternada, ápice e base cuneada com margens crenadas (Figura 3J e 4K).

Figura 4 - As fotos não representam o real tamanho das estruturas (ver escala na Figura 3). Cotilédones, eófilos, catáfilos e muda mostrando a filotaxia, respectivamente de Cecropia latiloba (A, B, C e D), Ficus insipida (E, F, G e H) e Allophylus amazonicus (I, J, K e L)

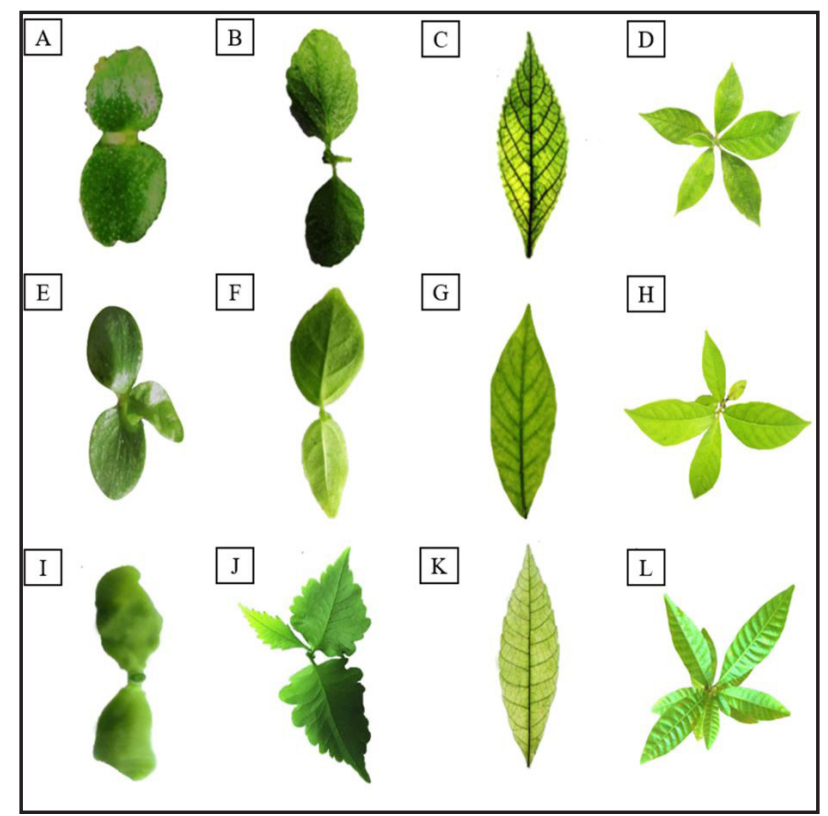

Fonte: Autores (2020) 
O conjunto de caracteres morfológicos das plântulas foi diferente em cada uma das três espécies (Tabela 1, Figura 4. D, H e L), possibilitando uma boa diferenciação das mesmas em campo.

Tabela 1 - Matriz de presença (1) ausência (0) não visualizadas (*) dos caracteres morfológicos das folhas de plântulas das espécies, Cecropia latiloba, Ficus insipida e Allophylus amazonicus

\begin{tabular}{llll}
\hline \multicolumn{1}{c}{ Caracteres Morfológicos Foliares } & CEC & FIC & ALL \\
\hline Cotilédones crassos & 0 & 0 & 1 \\
Cotilédones foliáceos & 1 & 1 & 0 \\
Cotilédones estreitos elípticos & 0 & 0 & 1 \\
Cotilédones com tricomas no limbo & 1 & $*$ & 0 \\
Eófilos com tricomas no limbo e pecíolo & 1 & 0 & 0 \\
Eófilos com tricomas só na nervação & 0 & 0 & 1 \\
Eófilos com margem crenada & 0 & 0 & 1 \\
Eófilos com margem serrada & 1 & 0 & 0 \\
Eófilos com margem inteira & 0 & 1 & 0 \\
Eófilos formato deltoide & 0 & 0 & 1 \\
Eófilos formato elíptico & 1 & 1 & 0 \\
Catáfilos com margem inteira & 0 & 1 & 0 \\
Catáfilos com margem serrilhada & 1 & 0 & 0 \\
Catáfilos com margem crenada & 0 & 0 & 1 \\
Catáfilos com filotaxia alternada & 1 & 1 & 1 \\
Catáfilos com folhas simples & 1 & 1 & 1 \\
Catáfilos com ápice e base cuneada & 1 & 1 & 1 \\
Incisão foliar pinatinérvea & 1 & 1 & 1 \\
Padrão de nervação broquidódroma & 1 & 1 & 0 \\
Padrão de nervação craspedódroma & 0 & 0 & 1 \\
\hline
\end{tabular}

Fonte: Autores (2020)

Em que: Cecropia latiloba (CEC), Ficus insipida (FIC), Allophylus amazonicus (ALL).

No padrão de incisão foliar, as três espécies apresentaram incisão pinatinérvea durante as fases (cotilédones, eófilos e catáfilos). Em relação ao padrão de nervação foliar nas diferentes fases do desenvolvimento, as espécies Cecropia latiloba e Ficus insipida apresentam padrão broquidódroma (Figura 5A e B), e Allophylus amazonicus 
padrão craspedódroma (Figura 5C). Nas nervuras terciárias, a espécie Cecropia latiloba (Figura 5A) apresenta nervuras opostas percorrentes (atravessam entre as secundárias sem ramificação em direção à base). Em Ficus insipida (Figura 5B), as nervuras são reticuladas aleatórias. Allophylus amazonicus (Figura 5C) exibe nervuras terciárias, alternas percorrentes, (atravessam as secundárias em padrão angular descontinuo sinuoso).

Figura 5 - Nervação terciária dos catáfilos aos 162 dias: A) Cecropia latiloba; B) Ficus insipida e C) Allophylus amazonicus

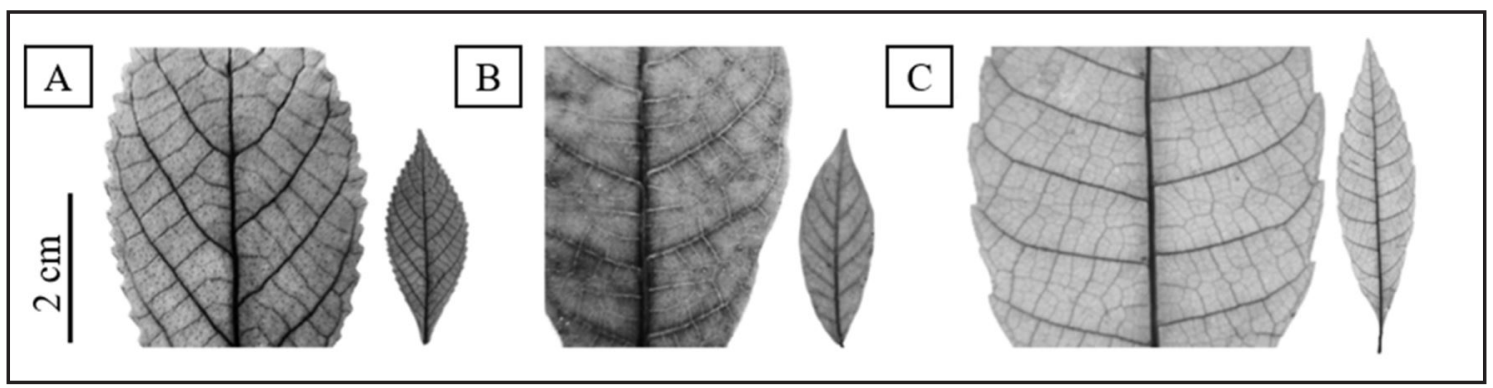

Fonte: Autores (2020)

\section{DISCUSSÃO}

A germinação das espécies foi favorecida em condições de casa de vegetação, em que nenhuma das espécies apresentou período de dormência, característica comum em sementes de espécies pioneiras, o que pode mantê-las no banco de sementes por meses ou anos até as condições ambientais serem adequadas ao seu desenvolvimento (PAROLIN, 2001). Para as três espécies estudadas, a germinação foi epígea, padrão que, segundo Parolin (2003), é comum em espécies de várzea, provavelmente devido ao alto teor de nutrientes desses ecossistemas, não necessitando grande quantidade de nutrientes nas reservas das sementes, como nas hipógeas. Sementes pequenas, como as das espécies deste estudo, estão associadas às plântulas fanerocotiledonares foliáceas (RESSEL et al., 2004), conforme encontrado para as três espécies. Westoby et al. 
(2002), em uma revisão, mostraram que, em geral, o desenvolvimento das plântulas em relação ao tamanho das sementes, está atribuído as condições ambientais, nas quais as sementes grandes podem ser mais adaptadas às severas condições ambientais, entretanto, o alagamento não foi levado em consideração. Além disso, Parolin (2000) não encontrou uma relação entre tamanho da semente de 58 espécies arbóreas de várzea e igapó e o nível de inundação.

Segundo Waldhoffe Parolin(2010), Cecropia latiloba exibe os cotilédones foliáceos e elípticos em consonância com os resultados encontrados neste estudo. A maioria das espécies dos estágios iniciais e tardios da várzea baixa apresentaram plântulas com cotilédones foliáceos (CONSERVA, 2007), capazes de realizar fotossíntese, permitindo maior independência às plântulas na incorporação de substâncias e mudanças no metabolismo (FERREIRA et al., 2005). Os cotilédones de Allophylus amazonicus foram semelhantes àqueles observados por Abreu et al. (2005) para a espécie Allophylus edulis (St.-Hil.) Radlk., na qual o embrião também se caracteriza como mais ou menos encurvado, com cotilédones crassos.

Os catáfilos das três espécies, aos 162 dias, a presentam folhas simples de filotaxia alternada, ápice e base cuneada, diferentemente dos presentes na fase adulta dessas espécies. Quando adulta, a espécie Cecropia latiloba apresenta folhas palmatífidas segmentadas (WITTMANN et al., 2010), enquanto Ficus insipida mantém as folhas simples, desde os eófilos até a fase adulta, porém com folhas elípticas a oblongas, com ápice agudo a levemente acuminado, base aguda a levemente truncada (PELISSARI; ROMANIUC NETO, 2014). Já Allophylus amazonicus apresenta, na fase adulta, folhas compostas unifoliadas (SOMNER et al., 2015). O fato dos eófilos de Cecropia latiloba e Allophylus amazonicus apresentarem estrutura foliar mais simples que os catáfilos e a planta adulta pode refletir as diferentes condições ambientais às quais a planta tem que se adaptar ao longo de seu desenvolvimento. A subdivisão da lâmina foliar em folíolos maximiza a área fotossintética e diminui a tensão mecânica potencial que uma superfície única e inteira sofreria (DENGLER; TSUKAYA, 2001). Filogeneticamente, 
as folhas compostas podem ter origem por lobação gradual da lâmina foliar com um aprofundamento intenso dos lobos até que eles atinjam a nervura principal gerando os folíolos, ou podem surgir por homeose, quando no local de formação de um determinado órgão, outro órgão ou características de outro órgão são expressos. Dessa maneira, as folhas compostas teriam surgido através de uma alteração no padrão de desenvolvimento das folhas simples, e várias estruturas simples (folíolos) teriam se formado onde uma lâmina foliar única deveria ser produzida (multiplicação) (DENGLER; TSUKAYA, 2001; BRAYBROOK; KUHLEMEIER, 2010).

As três espécies apresentaram padrão de incisão foliar pinatinérvea. Contudo, é importante salientar que na espécie Cecropia latiloba ocorre uma transição na morfologia das folhas, que em sua fase de plântula são pinatinérveas, e na fase adulta são lobadas e palmatinérveas. Segundo Berg (1978), todas as espécies do gênero Cecropia mostram uma transição gradual de folhas pinatinérveas a folhas palmatinérveas, lobadas, com nervuras radiais. Tais diferenças no padrão de incisão de plântulas demonstram que essa característica não é recomendada para ser usada na sua identificação.

Em relação à análise das nervações foliares, realizadas em mudas com 10 meses, as espécies de Cecropia latiloba e Ficus insipida apresentaram o mesmo padrão de nervação broquidódroma, diferenciando-se de Allophylus amazonicus que possui nervação craspedódroma. Segundo Somner et al. (2015), Allophylus amazonicus, em sua fase adulta, apresenta folhas compostas e os folíolos com nervura central proeminente na face adaxial, com tricomas curtos adpressos em ambas as faces. Todas as espécies estudadas apresentaram diferenças nas nervações terciárias; a espécie Cecropia latiloba apresenta nervuras opostas percorrentes, que se atravessam entre as secundárias sem ramificação em direção à base. Em Ficus insipida, as nervuras são reticuladas aleatórias, enquanto na espécie Allophylus amazonicus, as nervuras terciárias são alternas percorrentes, e atravessam as secundárias em angular descontinuo sinuoso. Dessa forma, a nervação terciária é um importante caracter para a separação das espécies. 
Embora a identificação de plântulas no campo não seja uma tarefa banal, devido às variações morfológicas durante o desenvolvimento (RIOS et al., 2016), análises da gênese e modificações foliares das três espécies estudadas permitiram caracterizá-las, tendo sido possível destacar características suficientes para a identificação e separação dessas espécies em campo, ainda no estágio de plântula. Diferenças morfológicas foliares entre as espécies, principalmente no formato das margens e das nervações terciárias, indicam que a morfologia foliar é uma importante ferramenta para auxiliar a identificação das espécies em campo, desde as fases iniciais do desenvolvimento. A identificação em campo evitaria esforços na produção de mudas usando aquelas disponíveis em bancos ativos de sementes, nos quais as plântulas podem ser facilmente reconhecidas e, consequentemente, utilizadas (LOPES; ROSA; PIEDADE, 2012).

Esses resultados podem contribuir para o entendimento da dinâmica de populações (PAOLI; BIANCONI, 2008), para o reconhecimento dos estágios sucessionais dentro da vegetação (FRIGIERI et al., 2016) e para estudos taxonômicos das espécies e sua identificação nas fases de plântulas em estudos de regeneração natural (BATTILANI; SANTIAGO; DIAS, 2011). Entretanto, e mais importante, os resultados podem ser uma importante ferramenta, especialmente para a recomposição de áreas degradadas de várzea, em que essas espécies são componentes-chave do estágio sucessional de pioneiras (WORBES et al., 1992).

\section{CONCLUSÃO}

A análise destas três espécies de várzea, Cecropia latiloba, Ficus insipida e Allophylus amazonicus permitiu concluir que as plântulas e mudas apresentam características morfológicas distintas desde suas folhas cotiledonares até os eófilos e catáfilos. Esse conjunto de dados acrescenta novas informações sobre o processo morfológico de desenvolvimento dessas espécies, podendo auxiliar sua identificação em campo e subsidiar a sistemática de espécies pioneiras. As características morfológicas das plântulas de várzea aqui identificadas, também podem ser úteis para a compreensão 
ecológica dos formatos foliares mais presentes nas plântulas das áreas alagáveis e sua relação com o estabelecimento das mesmas, em locais de estresse hídrico constante da Amazônia, bem como para a regeneração de áreas degradadas, utilizando plântulas coletadas no campo ou produzidas em casa de vegetação.

\section{REFERÊNCIAS}

ABREU, D. C. A. et al. Caracterização morfológica de frutos, sementes e germinação de Allophylus edulis (St.-Hil.) Radlk. (Sapindaceae). Revista Brasileira de Sementes, Londrina, v. 27, n. 2, p. 59-66, 2005.

BATTILANI, J. L.; SANTIAGO, E. F.; DIAS, E. S. Morfologia de frutos, sementes, plântulas e plantas jovens de Guibourtia hymenifolia (Moric.) J. Leonard (Fabaceae). Revista Árvore, Viçosa, MG, v. 35, n. 5, p. 1089-1098, 2011.

BERG, C. C.; ROSSELLI, P. F. Cecropia. Flora Neotropica. New York, v. 94, p. 168-172, 2005.

BERG, C. C. Espécies de Cecropia da Amazônia Brasileira. Acta Amazonica, Manaus, v. 8, n. 2, p. 149-182, 1978.

BRAYBROOK, S. A.; KUHLEMEIER, C. How a Plant Builds Leaves. Plant Cell, Bern, v. 22. p. 10061018, 2010.

COELHO, R. L. G. Estudos sistemáticos das espécies neotropicais de Allophylus L. (Sapindaceae). 2014. Tese (Doutorado) - Universidade Estadual de Campinas, Campinas, 2014.

CONSERVA, A. Germinação de sementes, emergência e recrutamento de plântulas de dez espécies arbóreas das várzeas das Reservas de Desenvolvimento Sustentável Amanã e Mamirauá, Amazônia Central. 2007. Tese (Doutorado) - Instituto Nacional de Pesquisas da Amazônia, Manaus, 2007.

DENGLER, N. G.; TSUKAYA, H. Leaf morphogenesis in dicotylendons: current issues. International Journal of Plant Science, [s. I.], v. 162, n. 3, p. 459-464, 2001.

ECODEBATE. Iniciativa prevê a recuperação de $\mathbf{3 0}$ mil hectares de áreas degradadas na Amazônia até 2023. [S. I.], 2017. Disponível em: https://www.ecodebate.com.br/2017/09/28/ iniciativa-preve-recuperacao-30-mil-hectares-de-areas-degradadas-na-amazonia-ate-2023/. Acessoem: jul. 2020.

FERREIRA, C. S. et al. Plant reproduction in the Central Amazonian floodplains: challenges and adaptations. AoBPlants, Oxford, v. 2010, plq009, 2010.

FERREIRA, C. S. et al. Tolerância da espécie Himatanthus sucuuba Wood. (Apocynaceae) ao alagamento na Amazônia Central. Acta Botanica Brasilica, São Paulo,v. 19, n.3, p. 425-429, 2005. 
FRIGIERI, F. F. et al. Guia de plântulas e sementes da Mata Atlântica do estado de São Paulo. Piracicaba: IPEF, 2016. 99 p.

GONÇALVES, E. G.; LORENZI, H. Morfologia vegetal: organografia e dicionário ilustrado de morfologia das plantas vasculares. 2. ed. São Paulo: Instituto Plantarum de Estudos da Flora, 2011. 512 p.

HICKEY, L.J. et al. Leaf Architecture working Group. Manual of leaf architecture: morphological description and categorization of dicotyledonous and net-veined monocotyledonous angiosperms. Washington: Smithsonian Institution, 1999. 65 p.

JOHANSEN, D. A. Plant microtechnique. New York: MacGraw-Hill Book Company, 1940. 46 p.

JUNK, W. J.; BAYLEY, P. B.; SPARKS, R. E. The flood pulse concept in river floodplain systems. Canadian Journal of Fisheries and Aquatic Sciences, Ottawa, n. 106, p. 110-127, 1989.

JUNK, W. J. et al. A classification of major naturally-occurring Amazonian lowland wetlands. Wetlands, Middleton, v. 31, n. 4, p. 623-640, 2011.

LOPES, A.; ROSA, S. M.; PIEDADE, M. T. F. Caracterização morfológica das plântulas de cinco espécies arbóreas da floresta estacional Semidecidual. Floresta, Curitiba, v. 42, n. 1, p. 105$114,2012$.

MELACK, J. M.; HESS, L. L. Remote sensing of the distribution and extent of Wetlands in the Amazon Basin. In: JUNK, W. J. et al. (ed.). Amazonian Floodplain Forests: ecophysiology, biodiversity and sustainable management. Dordrecht: Springer, 2010. p. 43-59.

NEVES, J. R. D. et al. Impact of climatic and hydrological disturbances on blackwater floodplain forests in Central Amazonia. Biotropica, Gainesville, v. 51, n. 4, p. 484-489, 2019.

OLIVEIRA, T. J. F. Plano de Recuperação de Áreas Degradadas: a importância do planejamento, manutenção e monitoramento. [S. I.]: Blog do Mata Nativa, 2019. Disponível em: https://www. matanativa.com.br/blog/plano-de-recuperacao-de-areas-degradadas/. Acesso em: jul. 2020.

PAOLI, A. A. S.; BIANCONI, A. Caracterização morfológica de frutos, sementes e plântulas de Pseudima frutescens (Aubl.) Radlk. (Sapindaceae). Revista Brasileira de Sementes, Londrina, v. 30, n. 2, p. 146-155, 2008.

PAROLIN, P. Fugitive and possessive establishment strategies in Amazonian floodplain pioneers. Flora, Jena, v. 198, n. 6, p. 444-460, 2003.

PAROLIN, P. Life history and environment of Cecropia latiloba in Amazonian floodplains. Revista de Biología Tropical, San José, v. 50, n. 2, p. 531-545, 2002.

PAROLIN, P. Seed germination and early establishment of 12 tree species from nutrient-poor Central Amazonian floodplains. Aquatic Botany, Amsterdam, v. 70, n. 2, p. 89-103, 2001.

PAROLIN, P. Seed mass in Amazonian floodplain forests with contrasting nutrient supplies. Journal of Tropical Ecology, Cambridge, v. 16, n. 3, p. 417-428, 2000. 
PELISSARI, G.; ROMANIUC NETO, S. Ficus L. (Moraceae) da Serra da Mantiqueira. Rodriguésia, Rio de Janeiro, v. 64, n. 1, p. 91-111, 2014.

PIEDADE, M. T. F. et al. Impactos ecológicos da inundação e seca a vegetação das áreas alagáveis amazônicas. In: NOBRE, C. A.; BORMA, L. S. (ed.). Eventos climáticos extremos na Amazônia: causas e consequências. São Paulo: Oficina de Textos, 2013. p. 268-305.

PRANCE, G. T. A terminologia dos tipos de florestas amazônicas sujeitas a inundação. Acta Amazonica, Manaus, v. 10, n. 3, p. 495-504, 1980.

RESSEL, K. et al. Ecologia morfofuncional de plântulas de espécies arbóreas da Estação Ecológica do Panga, Uberlândia, Minas Gerais. Brazilian Journal of Botany, São Paulo, v. 27, n. 2, p. 311-323, 2004.

RIOS, P. A. F. et al. Seed morphometry and germination of Aechmea costantinii (Mez) LB Sm. (Bromeliaceae). Revista Caatinga, Mossoró, v. 29, n. 1, p. 85-93, 2016.

SCHÖNGART, J. et al. Management criteria for Ficus insipida Willd. (Moraceae) in Amazonian white-water floodplain forests defined by tree-ring analysis. Annals of Forest Science, Les Ulis, v. 64, n. 6, p. 657-664, 2007.

SCHÖNGART, J. et al. Phenology and stem-growth periodicity of tree species in Amazonian floodplain forests. Journal of Tropical Ecology, Cambridge, v. 18, n. 4, p. 581-597, 2002.

$\mathrm{SIOLI}, \mathrm{H}$. The Amazon and its main affluents: hydrograph, morphology of the river courses, and river types. In: SIOLI, H. (ed.). The Amazon. Dordrecht: W. Junk Publishers, 1984. p. 127-165.

SOMNER, G. V. et al. Allophylus. Lista de Espécies da Flora do Brasil. Rio de Janeiro: Jardim Botânico do Rio de Janeiro, 2015. Disponível em: http://reflora.jbrj.gov.br/reflora/floradobrasil/ FB24683. Acesso em: jul. 2017.

SOUZA L. A. Morfologia e anatomia vegetal: célula, tecidos, órgãos e plântula. Ponta Grossa: UEPG, 2009. 259 p.

WALDHOFF, D.; JUNK, W. J.; FURCH, B. Responses of three central Amazonian tree species to drought and flooding under controlled conditions. International Journal of Ecology and Environmental Sciences, Jaipur, v. 24, p. 237-252, 1998.

WALDHOFF, D.; PAROLIN, P. Morphology and anatomy of leaves. In: JUNK, W. J. et al. (ed.). Amazonian floodplain forests: ecophysiology, biodiversity and sustainable management. Dordrecht: Springer, 2010. p. 179-202.

WESTOBY, M. et al. Plant Ecological strategies: some leading dimensions of variation between species. Annual Review of Ecology and Systematics, Danvers, v. 33, p. 125-159, 2002.

WITTMANN, F.; ANHUF, D.; JUNK, W. J. Tree species distribution and community structure of Central Amazonian várzea forests by remote sensing techniques. Journal of Tropical Ecology, Cambridge, v. 18, n. 6, p. 805-820, 2002.

WITTMANN, F. et al. Manual de árvores da várzea da Amazônia Central: taxonomia, ecologia e uso. Manaus: Editora INPA, 2010. 298 p. 
WITTMANN, F.; JUNK, W. J. The Amazon river basin. In: FINLAYSON, C. M. et al. (ed.). The Wetland book II: distribution, description and conservation. Heidelberg; Berlin; New York: Springer Verlag, 2016. p. 1-16.

WITTMANN, F.; JUNK, W. J.; PIEDADE, M. T. F. The várzea forests in Amazonia: flooding and the highly dynamic geomorphology interact with natural forest succession. Forest Ecology and Management, Amsterdam, v. 196, n. 2/3, p. 199-212, 2004.

WITTMANN, F.; PAROLIN, P. Aboveground roots in Amazonian white-water forests. Biotropica, Gainesville, v. 37, n. 4, p. 609-619, 2005.

WITTMANN, F.; SCHÖNGART, J.; JUNK, W. J. Phytogeography, species diversity, community structure and dynamics of central Amazonian floodplain forests. In: JUNK, W. J. et al. (ed.). Amazonian Floodplain Forests: ecophysiology, biodiversity and sustainable management. Dordrecht: Springer, 2010. p. 61-102.

WITTMANN, A. O. et al. Patterns of structure and seedling diversity along a flooding and successional gradient in Amazonian floodplain forests. Pesquisas. Botânica, São Leopoldo, v. 58, p. 119-138, 2007.

WORBES, M. et al. On the dynamics, floristic subdivision and geographical distribution of várzea forest in central Amazonia. Journal of Vegetation Science, [s. I.], v. 3, p. 553-564, 1992.

WORBES, M. The forest ecosystem of the floodplains. In: JUNK, W. J. (ed.). The Central Amazon floodplain: ecology of a pulsing system. Heidelberg: Springer, 1997. p. 223-266.

WORBES, M. Growth rings, increment and age of trees in inundation forests, savanas and a mountain forest in the neotropics. IAWA Bulletin, Beijing-Leiden, v. 10, n. 2, p. 109-122, 1989.

\section{Contribuição de Autoria}

\section{1 - Ivone Neri Santiago}

Bióloga

https://orcid.org/0000-0002-3388-5736•ins.ivone@gmail.com

Contribuiç̧ão: Investigação, Escrita - primeira redação

\section{2 - Maria Teresa Fernandez Piedade}

Bióloga, Pós-Doc., Pesquisadora

https://orcid.org/0000-0002-7320-0498•maitepp@inpa.gov.br

Contribuição: Conceituação, Supervisão, Obtenção de financiamento, Administração do projeto, Recursos, Escrita - revisão e edição 


\section{3 - Bianca Weiss}

Bióloga, Ma.

https://orcid.org/0000-0001-6398-9045 • biaweissalbuquerque@gmail.com

Contribuição: Conceituação, Supervisão, Investigação, Escrita - revisão e edição

\section{4 - Layon Oreste Demarchi}

Ecólogo, Me.

https://orcid.org/0000-0001-8441-2106•layon.lod@gmail.com

Contribuição: Escrita - revisão e edição

\section{5 - Aline Lopes}

Bióloga, Dra.

https://orcid.org/0000-0001-5771-4643•alopesmga@gmail.com

Contribuição: Conceituação, Supervisão, Metodologia, Escrita - revisão e edição

\section{Como citar este artigo}

Santiago, I. N.; Piedade, M. T. F.; Weiss, B.; Demarchi, L. O.; Lopes, A. Germinação de sementes e morfologia de plântulas de espécies pioneiras da várzea amazônica. Ciência Florestal, Santa Maria, v. 31, n. 1, p. 271-289, 2021. DOI 10.5902/1980509840676. Disponível em: https://doi. org/10.5902/1980509840676. Acesso em: xx mês abreviado 202x. 